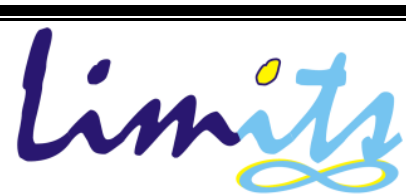

Journal of Mathematics and Its Applications

E-ISSN: 2579-8936

P-ISSN: 1829-605X

Vol. 16, No. 1, Agustus 2019, 11-25

\title{
Pencadangan Klaim IBNR dengan Pendekatan Distribusi Keluarga Tweedie pada Generalized Linear Model
}

\author{
Media Rahmawati' ${ }^{1}$, Isnani Darti², Marjono ${ }^{3}$ \\ 1,2,3 Departemen Matematika, Universitas Brawijaya Indonesia \\ e-mail:media.rahmawati@student.ub.ac.id ${ }^{1}$, isnanidarti@ub.ac.id ${ }^{2}$, marjono@ub.ac.id ${ }^{3}$
}

\begin{abstract}
Abstrak
Total klaim dalam asuransi umum merupakan jumlah dari klaim yang telah dilaporkan dan klaim incurred but not reported (IBNR). Cadangan klaim IBNR belum diketahui nominalnya, sehingga perlu diestimasi. Hasil estimasiyang akurat berpengaruh terhadap manajemen internal, investor, dan regulator suatu perusahaan asuransi.Dalam artikel ini, dibahas tentang estimasi cadangan klaim IBNR menggunakan metode GLM dengan pendekatan distribusi keluarga Tweedie, yaitu: Over Dispersed Poisson(ODP), Gamma, dan majemuk Poisson-Gamma. Analisis performa estimasi pencadangan dinilai dengan menggunakan mean squared error prediction (MSEP). Hasil pencadangan menunjukkan bahwa estimasi terbaik diperoleh dengan menggunakan metode GLM model ODP.
\end{abstract}

Kata Kunci: IBNR, Generalized Linear Model, distribusi keluarga Tweedie.

\begin{abstract}
Total claims in general insurance represent the number of reported claims and incurred but not reported yet claims (IBNR). The nominal reserves of IBNR claims are unknown, so they need to be estimated. Accurate estimation results affect the internal management, investors, and regulators of an insurance company. In this article, we discuss the estimation of IBNR claim reserves using the GLM method approached by Tweedie family distribution i.e. Over Dispersed Poisson (ODP), Gamma, and Poisson-compound Gamma. The performance analysis of reserves estimations is assessed using the mean squared error prediction (MSEP). The results show that the best estimation is obtained using the GLM method of the ODP model.
\end{abstract}

Keywords: IBNR, Generalized Linear Model, Family Tweedie distribution.

\section{Pendahuluan}

Kerugian total atau total klaim dalam asuransi umum merupakan jumlah dari klaim yang telah dilaporkan dan klaim yang telah terjadi namun belum dilaporkan oleh pihak tertanggung yang disebut sebagai Incurred But Not Reported atau IBNR. Pada saat penyusunan laporan akhir periode, pihak asuransi sebagai insurer telah mengetahui secara pasti nominal klaim yang telah dilaporkan oleh pihak tertanggung, namun berbeda dengan besarnya nominal IBNR yang belum diketahui secara pasti besar nominalnya sehingga IBNR perlu diestimasi secara tepat. Proses perhitungan estimasi IBNR disebut sebagai pencadangan klaim (claim reserving). Akurasi dalam 
penentuan nominal pencadangan secara langsung berpengaruh terhadap tiga aspek penting di dalam perusahaan asuransi, yaitu: manajemen internal, investor, dan regulator [1].

Tipe data yang digunakan dalam pncadangan klaim IBNR adalah data aggregate. Selanjutnya, data aggregate disusun menjadi segitiga run-off. Segitiga run-off digunakan sebagai alat bantu untuk melihat perilaku klaim dalam kurun waktu yang telah ditentukan. Metode pencadangan yang sering digunakan oleh aktuaris adalah metode Mack's Chain-Ladder (MCL) [2]. Namun, seiring berkembangnya teknologi dan perangkat lunak komputer yang dapat digunakan sebagai alat dalam perhitungan cadangan klaim, maka banyak dikembangkan teknik pencadangan yang bersifat stokastik salah satunya adalah GLM (Generalized Linear Model). Model stokastik GLM untuk pencadangan klaim IBNR dikembangkan oleh England dan Verrall (2002) [3]. Hartl pada tahun 2010 memanfaatkan model GLM untuk menentukan besar estimasi klaim pada segitiga run-off yang rumpang atau data yang tidak lengkap [4]. Pendekatan yang digunakan dalam penyelesaian permasalahan tersebut adalah model regresi non linear dan teori graph. Selanjutnya, pada tahun 2011, Björkwall dkk menggunakan model GLM dengan menambahkan efek smoothing dalam pencadangan klaim [8]. Perhitungan cadangan klaim IBNR GLM dipengaruhi oleh distribusi model EDF (Exponential Dispersion Family) karena model EDF sangat sesuai dengan distribusi pada klaim IBNR [5]. Selanjutnya, pada tahun 1997, Jørgensen mengungkapkan bahwa model EDF dicirikan oleh fungsi variansnya $V(\mu)$ [6]. Fungsi varians menggambarkan hubungan antara distribusi mean dan varians ketika parameter dispersi $\phi$ dipertahankan konstan. Y memiliki distribusi EDF dengan mean $\mu$ dan fungsi varians $V(\mu)$, maka $\operatorname{Var}[Y]=a(\phi) V(\mu)[7]$.

Model EDF dengan mean dan varians yang memiliki hubungan $V(\mu)=\mu^{p}$ untuk suatu nilai $p$ disebut sebagai model distribusi keluarga Tweedie. Model keluarga distribusi Tweedie adalah satu-satunya model eksponensial dispersi yang sifatnya sesuai untuk pemodelan data kontinu tak negatif dengan skala pengukuran yang acak. Karakteristik data tersebut sesuai dengan karakteristik data pada klaim IBNR. Keluarga distribusi ini terdiri dari beberapa distribusi seperti distribusi ODP(Over Dispersed Poisson), distribusi Gamma, dan distribusi majemuk Poisson-Gamma. Model majemuk Poisson-Gamma [10] merupakan perluasan dari model ODP [3, 9] dan model Gamma [8, 11].

Simulasi numerik dengan menggunakan data dari asuransi umum untuk beberapa line of business (LoB) dengan karakteristik data yang berbeda pada setiap LoB, disajikan pada bagian akhir artikel ini. Selanjutnya, nilai mean squared error prediction (MSEP) dimanfaatkan sebagai sarana dalam menilai performa hasil pencadangan klaim IBNR untuk masing-masing metode yang digunakan. 


\section{Data dan Notasi}

Data segitiga Run-Off komulatif diperoleh dari [12] LoB 1, LoB 2, LoB 3, dan LoB 4. Selanjutnya, data tersebut dirubah menjadi bentuk inkremental dengan bentuk umum pada Tabel 1 sebagai berikut.

Tabel 1. Struktur Segitiga Run-off Inkremental

\begin{tabular}{|c|ccccccc|}
\hline \multirow{2}{*}{ AY } & \multicolumn{7}{|c|}{ DY } \\
\cline { 2 - 7 } & 1 & 2 & $\cdots$ & $k$ & $\cdots$ & $I-1$ & $I$ \\
\hline 1 & $S_{1,1}$ & $S_{1,2}$ & $\cdots$ & $S_{1, k}$ & $\cdots$ & $S_{1, I-1}$ & $S_{1, I}$ \\
2 & $S_{2,1}$ & $S_{2,2}$ & $\cdots$ & $S_{2, k}$ & $\cdots$ & $S_{2, I-1}$ & \\
$\vdots$ & $\vdots$ & $\vdots$ & $\vdots$ & $\vdots$ & $\vdots$ & & \\
$\mathrm{I}$ & $S_{i, 1}$ & $S_{2,2}$ & $\cdots$ & $S_{i, k}$ & & & \\
$\vdots$ & $\vdots$ & $\vdots$ & $\vdots$ & & & & \\
$I-1$ & $S_{i-1,1}$ & $S_{i-1,2}$ & & & & & \\
$I$ & $S_{I, 1}$ & & & & & & \\
\hline
\end{tabular}

Segitiga run-off inkremental berukuran $I \times I$ dengan Accident Year (AY) digambarkan sebagai baris dengan $i \in\{1,2 \cdots I\}$ dan Development Year (DY) digambarkan sebagai kolom dengan $\in\{1,2 \cdots I\} . S_{i, k}$ adalah variabel acak yang menyatakan besarnya klaim inkremental pada AY- $i$ dan dibayarkan maksimum pada DY- $k$. Diasumsikan bahwa data $S_{i, k}$ untuk $i \in\{1,2 \cdots I\}$ dan $k \in\{1,2, \cdots, I-i+1\}$ telah diobservasi.

\section{$3 \quad$ Metode}

\subsection{Distribusi Keluarga Tweedie}

Distribusi keluarga Tweedie yang merupakan sub-keluarga dari distribusi Exponential Dispersion Family (EDF), pertama kali diperkenalkan oleh Tweedie (1984). EDF memiliki bentuk fungsi kepadatan peluang (fkp) $\pi(y: \theta, \phi)$ sebagai berikut

$$
\ln \pi(y ; \mu, \theta)=\frac{y \theta-b(\theta)}{a(\phi)}+c(y, \phi)
$$

dimana

- $y$ merupakan nilai data Y yang diobservasi, dalam permasalahan ini yaitu berupa $S_{i, k}$ untuk $i \in\{1,2 \cdots I\}$ dan $k \in\{1,2, \cdots, I-i+1\}$,

- $\theta$ disebut canonical parameter,

- $\phi$ adalah parameter disperse,

- $\quad b($.$) disebut cumulant function yang menentukan bentuk dari distribusi, dan$

- $\exp c(y, \phi)$ merupakan faktor yang menormalisasi data atau disebut sebagai normalizing factor. 
- Fungsi $a, b, c$ diasumsikan kontinu dan $b$ adalah fungsi satu-satu serta dapat diturunkan sebanyak dua kali dengan turunan pertama juga merupakan fungsi satu-satu.

Pemilihan $a, b, c$ dan karakteristik data observasi mempengaruhi anggota distribusi EDF. Distribusi Tweedie diperoleh dari EDF dengan pembatasan nilai $p$ sebagai berikut

$$
V(\mu)=\mu^{p}, p \leq 0 \text { atau } p \geq 1 .
$$

Jika diberikan $\operatorname{Var}[Y]=\alpha(\phi) V(\mu), \alpha(\phi)=\phi / w, \mu=E[Y]$, dan $Y$ merupakan data yang diobservasi, maka diperoleh $\operatorname{Var}[Y]=\phi \mu^{p}$. Nilai varians berbanding lurus terhadap nilai $p$, sehingga bentuk dari fungsi varians mengakibatkan cumulant function adalah

$$
b(\theta)=\frac{[(1-p) \theta]^{\frac{2-p}{1-p}}}{2-p} .
$$

Selanjutnya diperoleh

$$
\mu=[(1-p) \theta]^{\frac{1}{1-p}}
$$

Bentuk fkp dari distribusi keluarga Tweedie yang dinotasikan dengan $T w(\mu, \phi ; p)$ adalah

$$
\ln \pi(y ; \mu, \theta)=\left[\frac{y \mu^{1-p}}{(1-p)}-\frac{\mu^{2-p}}{(2-p)}\right] / \phi+c(y, \phi) \text {. }
$$

Tabel 2. Anggota Distribusi Keluarga Tweedie

\begin{tabular}{|l|c|c|c|c|}
\hline Distribusi & $p$ & $b(\theta)$ & $\mu$ & $\ln \pi(y ; \mu, \phi)$ \\
\hline Normal & 0 & $\frac{1}{2} \theta^{2}$ & $\theta$ & $\frac{\left\lfloor y \mu-\frac{1}{2} \mu^{2}\right\rfloor}{\phi}$ \\
Over-Dispersed Poisson & 1 & $\exp \theta$ & $\exp \theta$ & $\frac{\lfloor y \ln \mu-\mu\rfloor}{\phi}$ \\
Gamma & 2 & $\ln (-\theta)$ & $\frac{1}{-\theta}$ & $\frac{\left\lfloor-\frac{y}{\mu}-\ln \mu\right\rfloor}{\phi}$ \\
\hline
\end{tabular}

Tabel 2 menyajikan beberapa distribusi yang termasuk ke dalam anggota distribusi keluarga Tweedie. Menurut Jorgensen (1987), untuk nilai $1<p<2$ diidentifikasi sebagai distribusi majemuk Poisson-Gamma atau sering disebut sebagai Tweedie. Compound Poisson.

Distribusi Over Dispersed Poisson (ODP) berbeda dengan ditribusi Poisson. Varians pada distribusi ODP bernilai tidak sama dengan rataan hitung $\mu$, namun nilai variansnya berbanding lurus terhadap $\mu$ karena nilai variansnya dipengaruhi oleh $\phi$. Fkp dari ODP dinyatakan sebagai berikut

$$
\pi(y ; \mu, \phi)=\frac{\mu^{\frac{y}{\phi}} \exp \left(-\frac{\mu}{\phi}\right)}{\left(\frac{y}{\phi}\right) !}, y=0, \phi, 2 \phi, \text { dst. }
$$

dari persamaan (6) diperoleh 


$$
\begin{gathered}
E[Y / \phi]=\mu, \\
\operatorname{Var}[Y / \phi]=\phi \mu .
\end{gathered}
$$

Sedangkan untuk distribusi Gamma, bentuk fkp dinyatakakan sebagai berikut

$$
\operatorname{Var}[Y / \phi]=\phi \mu^{2} .
$$

Model distribusi majemuk Poisson-Gamma merupakan perluasan dari model distribusi Gamma. Wüthrich pada tahun 2016, berasumsi bahwa setiap data pada segitiga run-off terdiri dari $r_{i, k}$ pembayaran tunggal dengan mengikuti distribusi Gamma dengan $\tau_{i, k}$ sebagai mean atau rataan hitung dan $\gamma$ merupakan shape parameter. Selanjutnya, banyaknya pembayaran $r_{i, k}$ merupakan bentuk konkrit dari variable acak $R_{i, k}$. Banyaknya pembayaran $R_{i, k}$ dan besar dari pembayaran tunggal yang dinotasikan oleh $X_{i, k}^{(j)}$ dimodelkan secara stokastik. Selanjutnya, $R_{i, k}$ diasumsikan berdistribusi Poisson. Fungsi varians pada distribusi majemuk Poisson-Gamma adalah

$$
V[\mu]=\mu^{p} ; p \in(1,2)
$$

dengan bentuk fkp

$$
\pi(y ; \mu, \phi, p)=\left\{\sum_{r}\left(\frac{\left(\frac{1}{\phi}\right)^{\gamma+1} y^{y}}{(p-1)^{\gamma}(2-p)}\right)^{r} \frac{1}{r ! \Gamma(r \gamma) y}\right\} \exp \left\{\frac{1}{\phi}\left(y \frac{\mu^{1-p}}{1-p}-\frac{\mu^{2-p}}{2-p}\right)\right\},
$$

dengan, $p=\frac{\gamma+2}{\gamma+1}, p \in(1,2), p$ merupakan fungsi dari $\gamma$.

$$
\begin{aligned}
& \mu=\lambda \cdot \tau, \\
& \phi=\frac{\lambda^{1-p} \tau^{2-p}}{(2-p)} .
\end{aligned}
$$

dari persamaan diperoleh

$$
\begin{gathered}
E[Y / \phi]=\mu, \\
\operatorname{Var}[Y / \phi]=\phi \mu^{p} ; p \in(1,2)
\end{gathered}
$$

\subsection{Generalized Linear Model (GLM) untuk Pencadangan Klaim IBNR}

Analisis regresi linear adalah salah satu analisis yang mengukur hubungan antara variabel prediktor dengan variabel responnya. Asumsi yang harus dipenuhi dalam regresi linear adalah error berdistribusi normal dan memiliki varians yang konstan (homoskedastik) (Neter dkk., 1996). Namun, pada kenyataannya, asumsi tersebut seringkali tidak terpenuhi, misalnya error tidak berdistribusi normal dan variansnya tidak konstan (heteroskedastik), sehingga untuk menyempurnakan model tersebut, Nelder dan Baker pada tahun 1972 menciptakan suatu model bernama Generalized Linear Model (GLM). Dalam GLM variabel respon yang digunakan tidak 
berdistribusi normal saja akan tetapi seluruh distribusi yang termasuk ke dalam distribusi keluarga eksponensial. Selanjutnya, GLM dapat digunakan sebagai sarana dalam mengestimasi besar cadangan klaim IBNR. GLM dapat dinyatakan kedalam bentuk regresi

$$
\begin{gathered}
\mathbf{Y}_{\mathrm{i}}=\mathbf{x}_{\mathrm{i}}^{\prime} \mathbf{b}+\epsilon_{i}, \epsilon_{i} \sim N(0, \phi), \\
\mu=g^{-1}(\mathbf{X b})
\end{gathered}
$$

Transformasi struktur data segitiga run-off kedalam struktur data GLM ditunjukkan pada Tabel 3 berikut.

Tabel 3. Struktur GLM IBNR

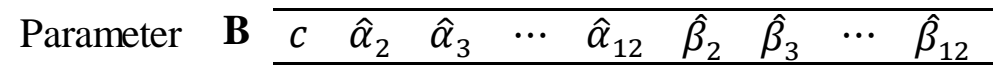

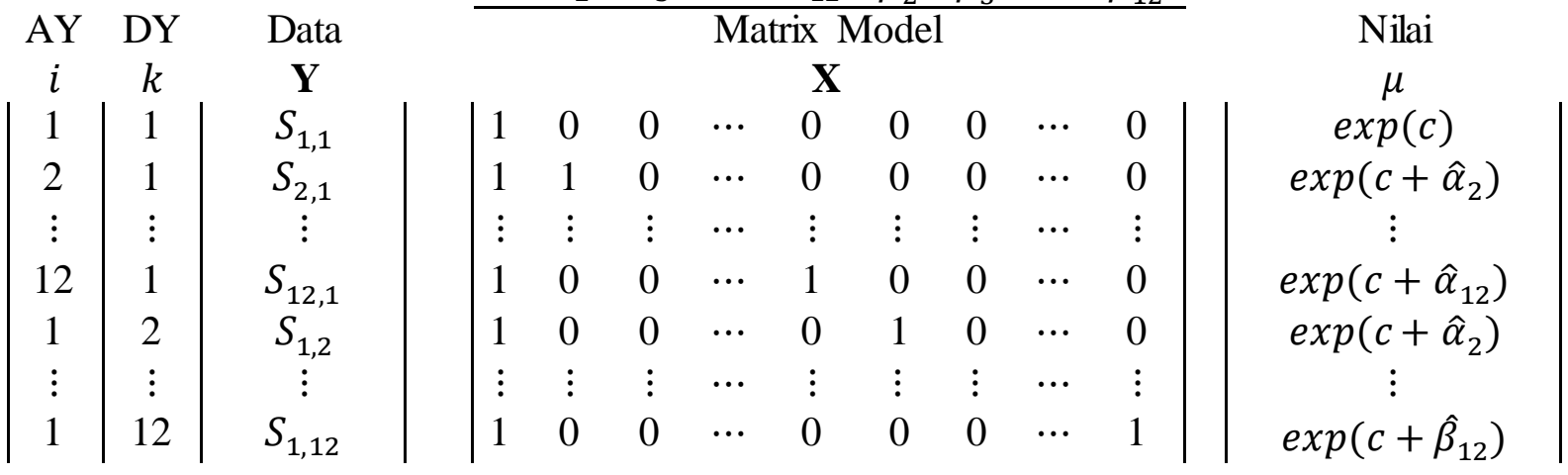

Masing-masing kolom pada matrik model $\mathrm{X}$ mempresentasikan variabel yang berpengaruh terhadap kolom vektor $\mathrm{Y}$ yang bersesuaian dan masing-masing baris pada matrik model $\mathrm{X}$ merupakan representasi dari setiap sel yang ada pada segitiga run-off. Semua entri pada matrik X berisi 0 dan 1. Nilai 1 berarti bahwa terdapat hubungan antara parameter dengan kolom serta baris yang membangun fitted value. Nilai 0 untuk sebaliknya. Vektor Y mempresentasikan klaim inkremental yang telah diobservasi.

GLM dalam IBNR menggunakan segetiga run-off berbentuk inkremental dengan asumsi-asumsi dasar sebagai berikut.

- Tidak terdapat faktor perkembangan. GLM hanya digunakan untuk memproyeksikan klaim terakhir pada data yang telah diobservasi.

- $S_{i, k}$ adalah bebas stokastik.

- Model cenderung over-parameterized sehingga dapat menyebabkan kinerja prediktor tidak maksimal.

Mengacu pada Renshaw dan Verall (1998), struktur GLM dalam pencadangan klaim adalah sebagai berikut:

1. $S_{i, k}$ berdistribusi EDF (Eksponential Distribution Family).

2. $E\left(S_{i, k}\right)=\mu_{i, k}$. 
3. $\eta_{i, k}=g\left(\mu_{i, k}\right)$, dengan $\eta_{i, k}$ adalah penduga linear. Selanjutnya, $g($.$) merupakan link$ function. Terdapat beberapa kemungkinan untuk link function pada setiap distribusi yaitu sebagai berikut. Untuk model ODP $g()=.\operatorname{Ln}($.$) , model Gamma g()=.\frac{1}{-(.)}$ atau $\operatorname{Ln}($.$) ,$ dan untuk model majemuk Poisson-Gamma $g()=.\operatorname{Ln}($.$) . Agar lebih sederhana, dalam$ artikel ini link function yang digunakan pada masing-masing model adalah log-linear

4. Prediktor linear $\eta_{i, k}=c+\hat{\alpha}_{i}+\hat{\beta}_{k}$, dengan $c$ adalah intercept, $\hat{\alpha}_{i}$ dan $\hat{\beta}_{k}$ adalah faktor efek yang mempengaruhi hasil estimasi cadangan klaim IBNR. Untuk menghindari overparameterized dan mengatasi permasalahan multikolinieritas yang muncul maka nilai $\hat{\alpha}_{1}=\hat{\beta}_{1}=0$ (reference cell technique).

Parameter dispersi $(\phi)$ dapat diperoleh dengan menentukan residual pearson sebagai langkah awal, yaitu

$$
r_{p}=\frac{\left(S_{i, k}-\hat{S}_{i, k}\right)}{\sqrt{S_{i, k}}},
$$

sehingga diperoleh $\hat{\phi}$ sebagai berikut

$$
\hat{\phi}=\frac{1}{n-p} \sum_{i=1}^{I} \sum_{k=1}^{I-1+1}\left(\frac{s_{i, k}-S_{i, k}}{\sqrt{S_{i, k}}}\right),
$$

dengan $n$ adalah jumlah data yang diobservasi dan $p$ adalah total parameter yang diestimasi. Estimasi parameter dalam GLM memanfaatkan fungsi log-likelihood. Formula log-likelihood secara berurutan untuk distribusi ODP, distribusi Gamma, dan distribusi majemuk PoissonGamma, telah dijabarkan di $[1,10]$ dan [11]. Cadangan klaim IBNR untuk setiap AY dan total secara berurutam diperoleh dengan

$$
\begin{gathered}
I B N R_{i}=\sum_{k=I+1-i}^{I} S_{i, k}, \\
I B N R=\sum_{i=1}^{I} I B N R_{i}
\end{gathered}
$$

\subsection{Mean Squared Error Prediction (MSEP) IBNRpada GLM}

Diasumsikan bahwa $S_{i, k}$ adalah independent, dan $S_{i, k}$ adalah penduga tak bias [8]. Selanjutnya, diasumsikan bahwa $\hat{\eta}_{i, k}$ adalah penduga GLM untuk $\eta_{i, k}=\ln \mu_{i, k}$. Bentuk umum imean square error prediction (MSEP)

$$
\begin{gathered}
\operatorname{MSEP} P_{I B N R_{i}}\left(I B N R_{i}\right)=E\left[\left(R_{i}-\hat{R}_{i}\right)^{2}\right]=E\left[\left(S_{i, k}-\hat{S}_{i, k}\right)^{2}\right]=\operatorname{MSEP}_{S_{i, k}}\left(S_{i, k}\right) \\
\operatorname{MSEP} P_{S_{i, k}}\left(\hat{S}_{i, k}\right)=E\left[\left(S_{i, k}-\hat{S}_{i, k}\right)^{2}\right]=\operatorname{Var}\left(S_{i, k}\right)+\operatorname{Var}\left(\hat{S}_{i, k}\right)
\end{gathered}
$$




$$
\approx \phi \cdot \mu_{i, k}^{p}+\left(\mu_{i, k}\right)^{2} \operatorname{Var}\left(\hat{\eta}_{i, k}\right) .
$$

Estimasi MSE pada masing-masing distribusi dapat diperoleh dengan menggunakan persamaan-persamaan sebagai berikut

$$
\begin{aligned}
& \widehat{m s e p}\left(\hat{S}_{i, k}\right) G L M-O D P \\
& =\sum_{k \in D} \phi \hat{\mu}_{i, k}+\sum_{k \in D} \hat{\mu}_{i, k}^{2} \operatorname{Var}\left(\hat{\eta}_{i, k}\right) \\
& +2 \sum_{k_{1}, k_{2 \in D}} \hat{\mu}_{i, k_{1}}, \hat{\mu}_{i, k_{2}} \operatorname{Cov}\left(\hat{\eta}_{i, k_{1}}, \hat{\eta}_{i, k_{2}}\right) \\
& \widehat{m s e p}\left(\hat{S}_{i, k}\right) \text { GLM - Gamma } \\
& =\sum_{k \in D} \phi \hat{\mu}_{i, k}^{2}+\sum_{k \in D} \hat{\mu}_{i, k}^{2} \operatorname{Var}\left(\hat{\eta}_{i, k}\right) \\
& +2 \sum_{k_{1}, k_{2 \in D}} \hat{\mu}_{i, k_{1}}, \hat{\mu}_{i, k_{2}} \operatorname{Cov}\left(\hat{\eta}_{i, k_{1}}, \hat{\eta}_{i, k_{2}}\right) \\
& \widehat{\operatorname{msep}}\left(\hat{S}_{i, k}\right) G L M \\
& \text { - Poisson Gamma } \\
& =\sum_{k \in D} \phi \hat{\mu}_{i, k}^{p}+\sum_{k \in D} \hat{\mu}_{i, k}^{2} \operatorname{Var}\left(\hat{\eta}_{i, k}\right) \\
& +2 \sum_{k_{1}, k_{2 \in D}} \hat{\mu}_{i, k_{1}}, \hat{\mu}_{i, k_{2}} \operatorname{Cov}\left(\hat{\eta}_{i, k_{1}}, \hat{\eta}_{i, k_{2}}\right)
\end{aligned}
$$

denga nilai $p \in(1,2)$.

Dalam menilai suatu performa dari hasil pencadangan dapat menggunakan Coefficient of Variation dengan menggunakan formula sebagai berikut.

$$
C V=\frac{\widehat{m s e p}}{I B N R} \times 100 \%
$$

\section{$4 \quad$ Hasil dan Pembahasan}

Data yang digunakan pada masing-masing LoB terdiri dari 12 AY yang dinotasikan sebagai $i$ dengan $i \in\{1,2, \cdots, 12\}$ dan 12DY dengan $k \in\{1,2, \cdots, 12\}$. Visualisasi data pada LoB 1 disajikan pada Gambar 1. 


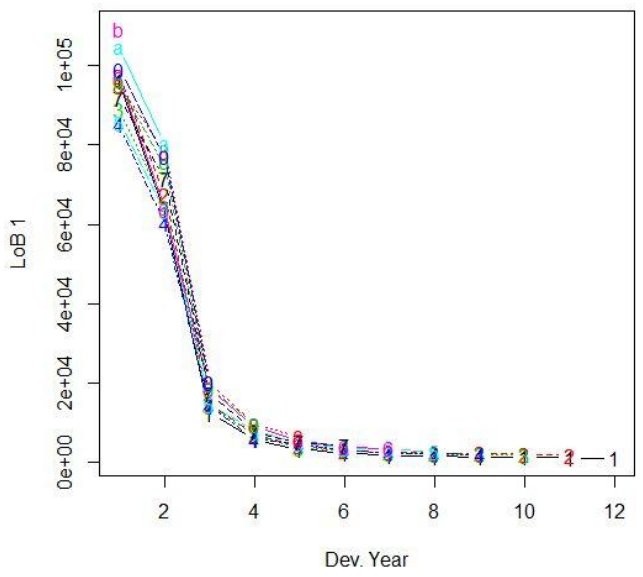

(a) Untuk seluruh AY

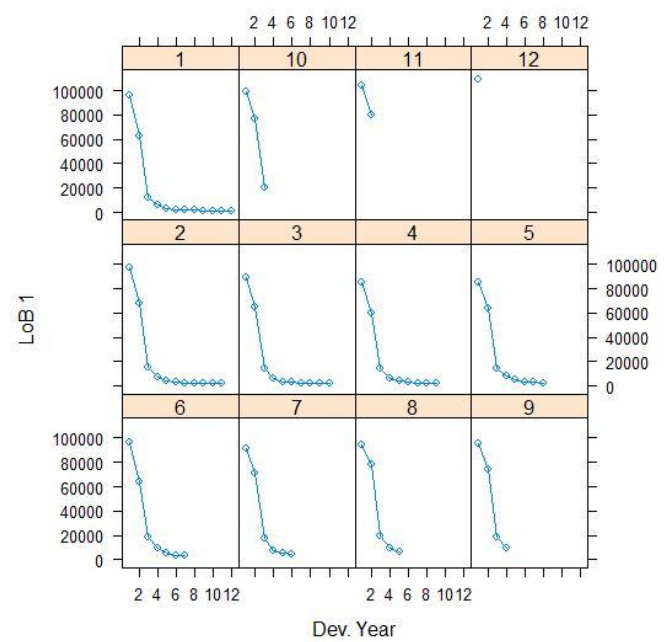

(b) masing-masing AY (kanan)

Gambar 1. Visualisasi Besar Klaim Inkremental pada LoB 1.

Dari Gambar 1, dapat dilihat bahwa trend yang terjadi pada besar klaim inkremental mengikuti distribusi eksponensial (decay). Langkah selanjutnya yaitu mentransformasi segitiga run-off kedalam struktur GLM seperti pada Tabel 3. Estimasi parameter dilakukan dengan memanfaatkan perangkat lunak R [13]. Hasil estimasi parameter yang diperoleh dapat dilihat di lampiran 2.

Untuk mendapatkan cadangan klaim IBNR pada setiap AY, maka besar klaim IBNR pada segitiga run-off bagian bawah ditentukan. Sebagai contohnya untuk menghitung $\hat{S}_{3,11}$ pada LoB 1 GLM-ODP adalah sebagai berikut

$$
\begin{aligned}
\hat{S}_{3,11} & =\mu_{3,11} \\
& =\exp \left(c+\hat{\alpha}_{12}+\hat{\beta}_{5}\right) \\
& =\exp (11,364790+0,237007-2,960910) \\
& =5.658,346 .
\end{aligned}
$$

Selanjutnya total cadangan klaim IBNR diperoleh dengan menggunakan persamaan (19). Berikut ini disajikan hasil estimasi cadangan klaim IBNR pada masing-masing LoB dengan menggunakan tiga model yang berbeda yaitu: GLM-ODP, GLM-Gamma, dan GLM-Mejemuk Poisson-Gamma.

Tabel 4. Hasil Estimasi Cadangan Klaim IBNR Metode GLM (dalam 1.000)

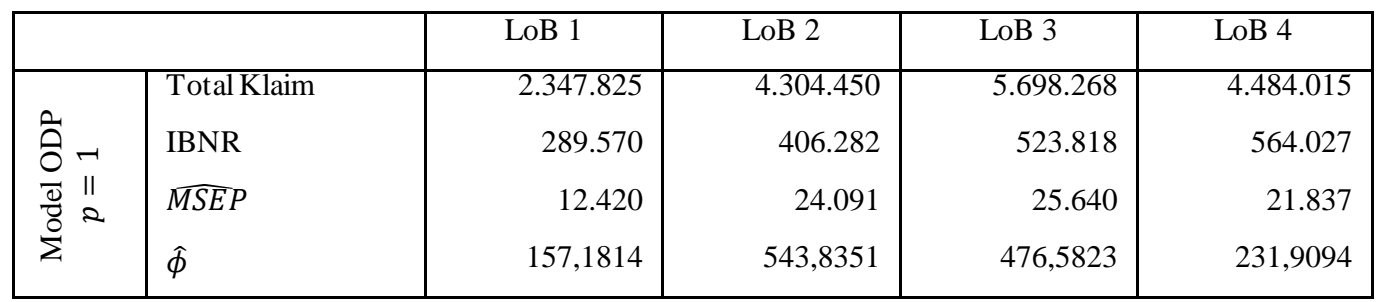




\begin{tabular}{|c|c|c|c|c|c|}
\hline & & LoB 1 & LoB 2 & LoB 3 & LoB 4 \\
\hline \multirow{4}{*}{ 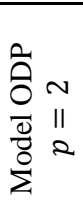 } & Total Klaim & 2.361 .376 & 4.314 .212 & 5.714 .737 & 4.510 .149 \\
\hline & IBNR & 303.121 & 416.044 & 540.287 & 590.161 \\
\hline & $\widehat{M S E P}$ & 19.539 & 57.825 & 39.796 & 28.812 \\
\hline & $\hat{\phi}$ & 0,01188 & 0,04607 & 0,01430 & 0,00723 \\
\hline \multirow{5}{*}{ 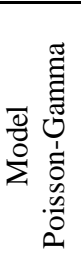 } & Total Klaim & 2.361 .233 & 4.304 .569 & 5.714 .617 & 4.509 .866 \\
\hline & IBNR & 302.978 & 406.401 & 540.167 & 589.878 \\
\hline & $\widehat{M S E P}$ & 18.595 & 22.215 & 37.838 & 27.611 \\
\hline & $\hat{\phi}$ & 0,00884 & 287,75 & 0,01104 & 0,00566 \\
\hline & $p$ & 1,99 & 1,01 & 1,99 & 1,99 \\
\hline
\end{tabular}

Dari Tabel 4 dapat diketahui bahwa besar nominal cadangan klaim IBNR pada LoB 1 untuk model GLM-ODP bernilai paling sedikit namun merupakan hasil pencadangan dengan performa terbaik. Hal ini juga berlaku pada LoB 3 dan LoB 4. Untuk LoB 2, hasil pencadangan dengan model GLM-Majemuk Poisson-Gamma menunjukkan performa terbaik yang ditunjukkan dari nilai $\widehat{m s e p}$ yang terkecil. Selain dengan menggunakan besar $\widehat{m s e p}$ dalam menilai performa, aktuaris dapat memanfaatkan nilai CV pada persamaan (25). Visualisasi hasil perhitungan CV pada keempat LoB dapat dilihat pada Gambar 2. Nilai $\phi$ pada model GLM-ODP merupakan besar parameter dispersi, sedangkan pada model GLM-Gamma merupakan shape parameter.

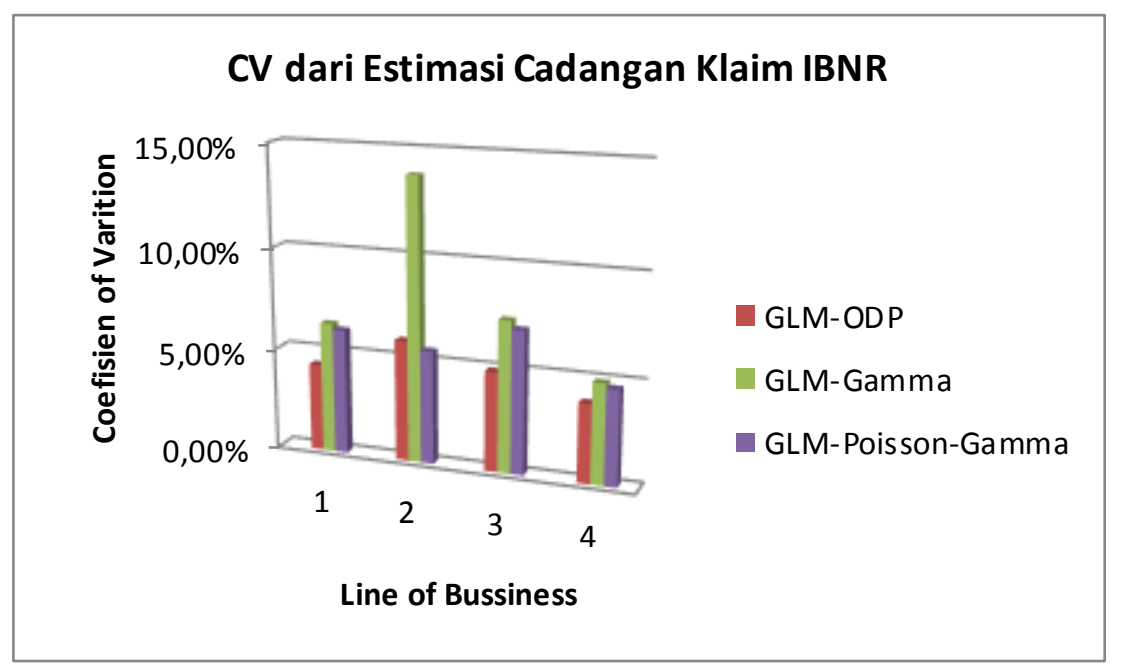

Gambar 2. CV Estimasi Cadangan Klaim IBNR

Informasi standardized residual sangat menguntungkan aktuaris maupun pihak yang terkait, karena aktuaris dapat mengetahui keberadaan outliers. Plotting sebaran standardized residual VS Fitted Value disajikan pada Gambar 3. 


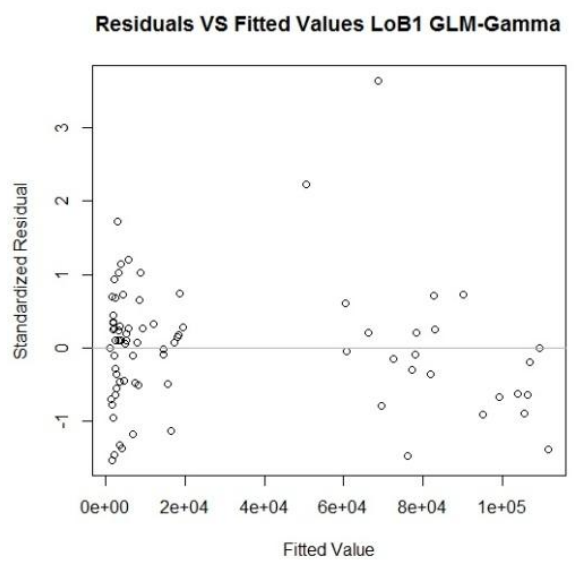

(a) Model Gamma LoB 1

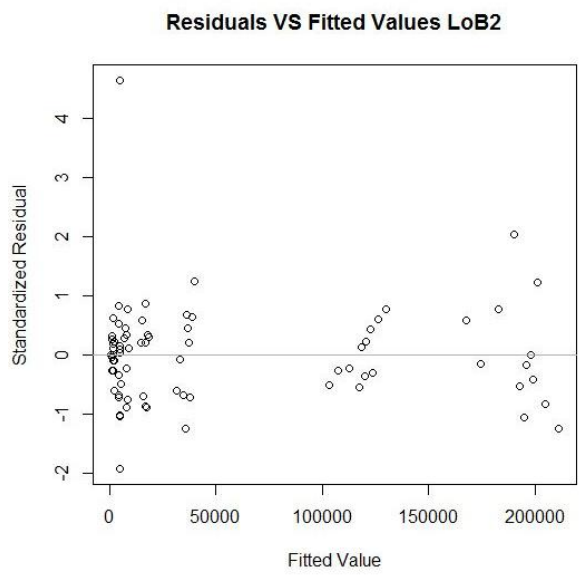

(c) Model ODP LoB 2

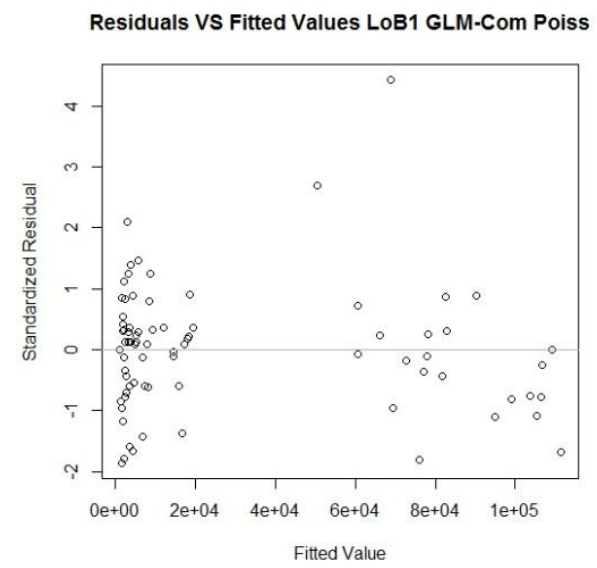

(b) Model Majemuk Poisson-Gamma LOB 1

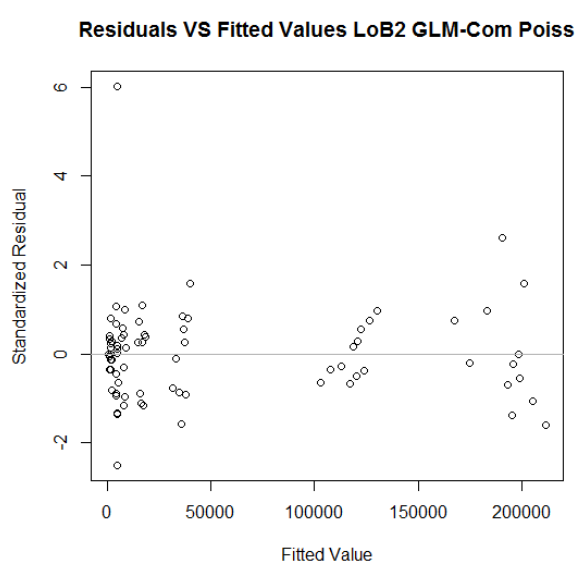

(d) Model Majemuk Poisson-Gamma LOB 2

Gambar 3. Standardized Residual VS Fitted Value

Melalui Gambar 3 dapat ditunjukkan bahwa besar nilai $p$ pada model majemuk PoissonGamma sangat mempengaruhi sebaran standardized residul (SR). Untuk nilai $p$ yang mendekati nilai $p=1$ (Gambar 3 (d)), maka sebaran SR memiliki pola yang serupa dengan SR pada model GLM-ODP (Gambar 3 (c)). Sedangkan untuk nilai $p$ yang mendekati nilai $p=2$ (Gambar 3 (b)), sebaran SR memiliki pola yang serupa dengan sebaran SR pada GLM-Gamma (Gambar 3 (a)).

\section{Simpulan}

Hasil estimasi cadangan klaim IBNR terbaik pada LoB 1, LoB 3, dan LoB 4 diperoleh dengan menggunakan model GLM-ODP, sedangkan untuk LoB 2 menggunakan model GLMmajemuk Poisson-Gamma. Nilai $p$ pada model GLM-majemuk Poisson Gamma berpengaruh terhadap sebaran standardized residual. Estimasi terbaik pada LoB 1 adalah 12.420, LoB 2 sebesar 22.215, sedangkan untuk LoB 3 adalah 523.818, dan LoB 4 adalah sebesar 564.027 (dalam 1.000). 


\section{Daftar Pustaka}

[1] J. Friedland and K. Llp, "Casualty Actuarial Society Estimating Unpaid Claims Using Basic Techniques," 2010.

[2] T. Mack, "Distribution-free Calculation of the Standard Error of Chain Ladder Reserve Estimates," ASTIN Bull., vol. 23, no. 02, pp. 213-225, 2006.

[3] B. P. D. England and R. J. Verrall, "Stochastic Claims Reserving In General Insurance," Int. J., vol. 544, no. January, 2002.

[4] T. Hartl, "Fitting a GLM to Incomplete Development Triangles," pp. 1-36, 2010.

[5] P.McCullagh and J.A. Nelder,“Generalized Linear Models,” CRC Press., vol. 37, 1989.

[6] B. Jorgensen, "The Theory Of Dispersion Models," CRC Press, 1997.

[7] G. Taylor, and G. McGuire, "Stochastic Loss Reserving Using Generalized Linear Models," CAS Monograph, vol. 3, 2016.

[8] S. Björkwall, S. O. Hössjer, E. Ohlsson, and R. Verrall, "A Generalized Linear Model With Smoothing Effects For Claims Reserving," Insurance: Mathematics and Economics., vol. 49, no. 1, p. 27-37, 2011.

[9] A. E. Renshaw, and R. J. Verrall, "A Stochastic Model Underlying The Chainladder Technique,” British Actuarial Journal, vol. 4, no. 4, p. 903-923, 1998.

[10] M. V. Wüthrich, “Claims Reserving Using Tweedie's Compound Poisson Model.”ASTIN Bulletin: The Journal of the IAA, 33(2):331-346, 2016.

[11] T. Mack, “Schadenversicherungsmathematik," Verlag Vers.swirtschaft, Karisruhe, 1997.

[12] M. V. W $\ddot{\mathrm{u}}$ thrich, Non-life insurance: mathematics \& statistics. https://ssrn.com/abstract=2319328, Diakses pada 31 Januari 2018, 2017.

[13] A. Carrato, F. Concina, M. Gesmann, D. Murphy, M. V. Wüthrich, and W. Zhang, “Claims Reserving with R: Chainladder-0.2. 5 Package Vignette," 2017. 


\section{Lampiran}

\section{Lampiran 1. Pseucode}

Tabel L1. Pseucode R untuk metode GLM: ODP, Gamma, dan Compound-Poisson

\begin{tabular}{|l|ll|}
\hline ODP & $\begin{array}{l}\text { fit1<-glmReserve(triinc,var.power=1, link.power=0, cum=FALSE, } \\
\text { mse.method=c("formula"), nb=FALSE) } \\
\text { summary(fit1,type="model") }\end{array}$ \\
\hline Gamma & $\begin{array}{l}\text { fit2<-glmReserve(triinc,var.power=2, link.power=0, cum=FALSE, } \\
\text { mse.method=c("formula"), nb=FALSE) } \\
\text { summary(fit2,type="model") }\end{array}$ \\
\hline $\begin{array}{l}\text { Compound- } \\
\text { Poisson }\end{array}$ & $\begin{array}{l}\text { fit3<-glmReserve(triinc,var.power=NULL, } \\
\text { mse.method=c("formula"),nb=FALSE) } \\
\text { summary(fit3,type="model") }\end{array}$ \\
\hline
\end{tabular}

"var.power" merupakan nilai $p$ pada $V(\mu)=\mu^{p}$. Untuk $p=1$ merupakan GLM-ODP, $p=2$ adalah GLM-Gamma, dan jika $p=$ NULL diasumsikan data berdistribusi Compound-Poisson. Untuk index "link.power $=0$ " menghasilkan link function berupa log-linear. "cum=FALSE" berarti bahwa data yang diolah berupa segitiga run-off incremental. "mse.method=c("formula")" berarti bahwa perhitungan $\widehat{m s e p}$ secara analitik bukan melalui teknik bootstrap. Untuk "nb=FALSE", hal ini mengindikasikan bahwa proses perhitungan tidak menggunakan distribusi Negatif Binomial. 
Lampiran 2. Hasil Estimasi

Tabel L2. Output Estimasi Parameter oleh R

\begin{tabular}{|c|c|c|c|c|c|c|c|c|c|c|c|c|}
\hline \multirow{3}{*}{ Parameter } & \multicolumn{6}{|c|}{ LoB 1} & \multicolumn{6}{|c|}{ LoB 2} \\
\hline & \multicolumn{2}{|c|}{ ODP } & \multicolumn{2}{|c|}{ Gamma } & \multicolumn{2}{|c|}{ Poi-Gamma } & \multicolumn{2}{|c|}{ ODP } & \multicolumn{2}{|c|}{ Gamma } & \multicolumn{2}{|c|}{ Poi-Gamma } \\
\hline & Estimasi & Std Error & Estimasi & Std Error & Estimasi & Std Error & Estimasi & Std Error & Estimasi & Std Error & Estimasi & Std Error \\
\hline (Intercept) & 11.364790 & 0.030346 & 11.13898 & 0.04783 & -11.14117 & $0.04770^{\circ}$ & 12.15722 & 0.03942 & 11.90052 & 0.09419 & 12.15553 & 0.03999 \\
\hline factor (origin) 2 & 0.077284 & 0.039892 & 0.27062 & 0.04648 & 0.26859 & 0.04670 & 0.05540 & 0.05242 & 0.20681 & 0.09153 & 0.05616 & 0.05313 \\
\hline factor (origin) 3 & 0.006202 & 0.040707 & 0.18321 & 0.04819 & 0.18140 & 0.04840 & -0.03926 & 0.05373 & 0.19870 & 0.09490 & -0.03803 & 0.05444 \\
\hline factor (origin) 4 & -0.036865 & 0.041281 & 0.18578 & 0.04998 & 0.18346 & 0.05018 & -0.12828 & 0.05507 & 0.12519 & 0.09843 & -0.12675 & 0.05577 \\
\hline factor (origin) 5 & 0.006292 & 0.040967 & 0.32217 & 0.05201 & 0.31877 & 0.05216 & -0.08651 & 0.05454 & 0.26332 & 0.10241 & -0.08439 & 0.05525 \\
\hline factor $(0 x i g i n) 6$ & 0.095503 & 0.040217 & 0.41219 & 0.05440 & 0.40886 & 0.05450 & 0.02286 & 0.05313 & 0.55570 & 0.10712 & 0.02602 & 0.05384 \\
\hline factor (origin) 7 & 0.093292 & 0.040405 & 0.36507 & 0.05735 & 0.36215 & 0.05741 & 0.01163 & 0.05348 & 0.31792 & 0.11294 & 0.01369 & 0.05421 \\
\hline factor (origin) 8 & 0.167336 & 0.039897 & 0.48343 & 0.06117 & 0.48000 & 0.06113 & 0.10375 & 0.05249 & 0.41436 & 0.12046 & 0.10598 & 0.05322 \\
\hline factor (origin) 9 & 0.138652 & 0.040452 & 0.42638 & 0.06641 & 0.42323 & 0.06627 & 0.07364 & 0.05320 & 0.37409 & 0.13077 & 0.07569 & 0.05396 \\
\hline factor (origin) 10 & 0.172104 & 0.040596 & 0.43651 & 0.07423 & 0.43371 & 0.07391 & 0.04350 & 0.05433 & 0.32015 & 0.14618 & 0.04533 & 0.05512 \\
\hline factor (origin) 11 & 0.206970 & 0.041338 & 0.43940 & 0.08769 & 0.43712 & 0.08705 & 0.02764 & 0.05635 & 0.29200 & 0.17267 & 0.02939 & 0.05720 \\
\hline factor (or1g1n) 12 & 0.237007 & 0.048570 & 0.46281 & 0.11904 & 0.46063 & 0.11797 & 0.03903 & 0.06557 & 0.29572 & 0.23441 & 0.04072 & 0.06665 \\
\hline factor (dev) 2 & -0.303175 & 0.018908 & -0.31086 & 0.04648 & -0.31073 & 0.04607 & -0.48465 & 0.02597 & -0.49399 & 0.09153 & -0.48469 & 0.02636 \\
\hline factor (dev) 3 & -1.725472 & 0.033345 & -1.74480 & 0.04819 & -1.74446 & 0.04795 & -1.66467 & 0.04207 & -1.68338 & 0.09490 & -1.66473 & 0.04240 \\
\hline factor (dev) 4 & $-2,477377$ & 0.049372 & -2.49664 & 0.04998 & -2.49628 & 0.04985 & -2.43138 & 0.06234 & -2.44968 & 0.09843 & -2.43137 & 0.06246 \\
\hline factor (dev)s & -2.960910 & 0.066022 & -2.97640 & 0.05201 & -2.97606 & 0.05196 & -3.14704 & 0.09306 & -3.16471 & 0.10241 & -3.14696 & 0.09276 \\
\hline factor (dev) 6 & -3.272700 & 0.082654 & -3.27155 & 0.05440 & -3.27140 & 0.05442 & -3.62709 & 0.12656 & -3.63306 & 0.10712 & -3.62684 & 0.12569 \\
\hline factor (dev)? & -3.489535 & 0.099631 & -3.48764 & 0.05735 & -3.48742 & 0.05745 & -3.69092 & 0.14136 & -3.79060 & 0.11294 & -3.69085 & 0.14033 \\
\hline factor (dev) 8 & -3.681398 & 0.120690 & -3.64835 & 0.06117 & -3.64850 & 0.06136 & -4.47991 & 0.22967 & -4.43278 & 0.12046 & -4.47925 & 0.22671 \\
\hline factor (dev) 9 & -3.787085 & 0.141969 & -3.72288 & 0.06641 & -3.72334 & 0.06670 & -4.68016 & 0.28188 & -4.58569 & 0.13077 & -4.67929 & 0.27788 \\
\hline factor (dev) 10 & -3.899364 & 0.171806 & -3.80902 & 0.07423 & -3.80980 & 0.07465 & -4.87557 & 0.35295 & -4.75474 & 0.14618 & -4.87449 & 0.34755 \\
\hline ractor (dev) 11 & -4.084645 & 0.229250 & -3.97405 & 0.08769 & -3.97504 & 0.08835 & -5.01672 & 0.45860 & -4.85087 & 0.17267 & -5.01549 & 0.45123 \\
\hline factor (dev) 12 & -4.326884 & 0.372720 & -4.10108 & 0.11904 & -4.10326 & 0.12025 & -5.34487 & 0.77449 & -5.08818 & 0.23441 & -5.34318 & 0.76016 \\
\hline
\end{tabular}


Generalized Linear Model

Tabel L2. Output Estimasi Parameter oleh R (Lanjutan)

\begin{tabular}{|c|c|c|c|c|c|c|c|c|c|c|c|c|}
\hline \multirow[t]{2}{*}{ Parameter } & \multicolumn{6}{|c|}{ LoB 3} & \multicolumn{6}{|c|}{ LoB 4} \\
\hline & \multicolumn{2}{|c|}{ ODP } & \multicolumn{2}{|c|}{ Gamma } & \multicolumn{2}{|c|}{ Poi-Gamma } & \multicolumn{2}{|c|}{ ODP } & \multicolumn{2}{|c|}{ Gamma } & \multicolumn{2}{|c|}{ Poi-Gamma } \\
\hline (Incercept) & 12.518806 & $0.031850^{\circ}$ & 12.44206 & 0.05248 & 12.44231 & 0.05221 & 12.034883 & 0.027025 & 11.89421 & 0.03732 & -11.89547 & 0.03727 \\
\hline factor $($ or $1 \mathrm{~g} \mid \mathrm{n}) 2$ & 0.031117 & 0.042851 & -0.04832 & 0.05100 & -0.04710 & 0.05118 & 0.044541 & 0.036010 & 0.10976 & 0.03626 & 0.10916 & 0.03650 \\
\hline factor (origin) 3 & -0.073534 & 0.044065 & -0.09005 & 0.05287 & -0.08942 & 0.05304 & -0.017040 & 0.036692 & 0.06295 & 0.03760 & 0.06222 & 0.03793 \\
\hline factor $(0 \mathrm{r} 1 \mathrm{~g} 1 \mathrm{n}) 4$ & -0.113363 & 0.044602 & -0.05181 & 0.05484 & -0.05217 & 0.05497 & -0.001187 & 0.036660 & 0.11762 & 0.03899 & 0.11654 & 0.03921 \\
\hline faetor (origin) 5 & -0.088199 & 0.044400 & 0.04410 & 0.05706 & 0.04311 & 0.05714 & 0.044583 & 0.036367 & 0.19427 & 0.04057 & 0.19288 & 0.04077 \\
\hline factor $(0 \times 1 \mathrm{~g} 1 \mathrm{n}) 6$ & -0.037415 & 0.043927 & 0.16100 & 0.05969 & 0.15954 & 0.05970 & 0.081989 & 0.036160 & 0.34265 & 0.04244 & 0.33995 & 0.04259 \\
\hline factor (or 1 gin) ? & 0.005696 & 0.043575 & 0.17646 & 0.06293 & 0.17530 & 0.06286 & 0.114449 & 0.036034 & 0.34099 & 0.04474 & 0.33860 & 0.04486 \\
\hline factor (oxigin) 8 & 0.052632 & 0.043235 & 0.21428 & 0.06712 & 0.21308 & 0.06695 & 0.174117 & 0.035702 & 0.39308 & 0.04772 & 0.39077 & 0.04778 \\
\hline factor $(0 ; 1 g 1 n) 9$ & 0.095885 & 0.043058 & 0.22753 & 0.07286 & 0.22659 & 0.07255 & 0.220256 & 0.035560 & 0.41872 & 0.05181 & 0.41661 & 0.05178 \\
\hline factor $(0$ r $1 \mathrm{gin}) 10$ & 0.129009 & 0.043212 & 0.22210 & 0.08145 & 0.22155 & 0.08092 & 0.289893 & 0.035365 & 0.45645 & 0.05791 & 0.45474 & 0.05774 \\
\hline factor $(0 \times 1 \mathrm{~g} 1 \mathrm{n}) 11$ & 0.051089 & 0.045222 & 0.13313 & 0.09621 & 0.13280 & 0.09534 & 0.268219 & 0.036384 & 0.41001 & 0.06841 & 0.40873 & 0.06802 \\
\hline factor (or1gin) 12 & 0.039988 & 0.051856 & 0.11673 & 0.13061 & 0.11649 & 0.12914 & 0.303248 & 0.041791 & 0.44392 & 0.09287 & 0.44266 & $0.0921 \mathrm{~s}$ \\
\hline factor (dev) 2 & -0.641383 & 0.021353 & -0.64854 & 0.05100 & -0.64842 & 0.05045 & -0.429087 & 0.016802 & -0.43344 & 0.03626 & -0.43338 & 0.03601 \\
\hline factor (dev) 3 & -1.936696 & 0.037058 & -1.95603 & 0.05287 & -1.95571 & 0.05249 & -1.873756 & 0.030498 & -1.89249 & 0.03760 & -1.89220 & 0.03748 \\
\hline factor (dev) 4 & -2.625591 & 0.053746 & -2.64669 & 0.05484 & -2.64631 & 0.05456 & -2.598459 & 0.045085 & -2.61890 & 0.03899 & -2.61847 & 0.03896 \\
\hline tactor (dev) 5 & -3.191056 & 0.075073 & -3.20331 & 0.05706 & -3.20304 & 0.05688 & -3.030895 & 0.059207 & -3.04553 & 0.04057 & -3.04526 & 0.04060 \\
\hline factor (dev) 6 & -3.714192 & 0.104063 & -3.70664 & 0.05969 & -3.70654 & 0.05962 & -3.356739 & 0.074685 & -3.36002 & 0.04244 & -3.35985 & 0.04253 \\
\hline factor (dev)? & -4.025230 & 0.131404 & -3.99675 & 0.06293 & -3.99688 & 0.06296 & -3.498090 & 0.086927 & -3.48316 & 0.04474 & -3.48320 & 0.04499 \\
\hline factor (dev) 8 & -4.232676 & 0.159552 & -4.17808 & 0.06712 & -4.17836 & 0.06725 & -3.754989 & 0.108566 & -3.69852 & 0.04772 & -3.69902 & 0.04795 \\
\hline factor (dev) 9 & -4.432476 & 0.195906 & -4.35020 & 0.07286 & -4.35075 & 0.07313 & -3.814083 & 0.125378 & -3.73845 & 0.05181 & -3.73914 & 0.05212 \\
\hline factor (dev) 10 & -4.703006 & 0.255572 & -4.59459 & 0.08145 & -4.59545 & 0.08191 & -3.958183 & 0.155164 & -3.86778 & 0.05791 & -3.86857 & 0.05835 \\
\hline factor (dev) 11 & -4.913536 & 0.342523 & -4.79851 & 0.09621 & -4.79932 & 0.09695 & -3.953756 & 0.188309 & -3.84974 & 0.06841 & -3.85065 & 0.06900 \\
\hline factor (dev) 12 & -5.485300 & 0.649062 & -5.40856 & 0.13061 & -5.40880 & 0.13217 & -4.108281 & 0.290607 & -3.96761 & 0.09287 & -3.96897 & 0.09387 \\
\hline
\end{tabular}

